\title{
Maleik Anhidrit Vinil Asetat Kopolimerinin Ester ve Karboksilat Tuz Türevlerinin Sentezi ve Karakterizasyonu
}

\author{
Ümit M. KOÇYİĞİT ${ }^{1}$, Hacı B. ZENGİN² \\ ${ }^{I}$ Cumhuriyet Üniversitesi Sağlık Hizmetleri Meslek Yüksekokulu 58140 SIVAS \\ ${ }^{2}$ Cumhuriyet Üniversitesi Fen Fakültesi Kimya Bölümü 58140 SiVVAS
}

Received: 11.03.2015; Accepted: 14.04.2015

\begin{abstract}
Özet. Yapılan çalışma ile kopolimer türevlerinin 1sısal kararlılığını artırmak amaçlanmıştır. Bu amaçla maleik anhidrit-vinil asetat (MAVA) kopolimeri n-propil alkol, n-butil alkol ve amonyak ile tepkimeye sokularak onun monoester ve karboksilat tuzu türevleri elde edildi. Bu türevlerin yapısal karakterizasyonu Fourier dönüşümlü infrared spektroskopisi (FTIR) ile yapılırken ısısal analizlerde Termogravimetrik Analiz (TGA) kullanıldı. Araştırma sonucunda TGA eğrilerine göre 1sıya karşı kararlılıkları karşılaştırıldığında karboksilat türevlerinin en kararlı olduğu ve en az kararlı olanın ise ester türevlerinin olduğu görülmüştür.
\end{abstract}

Anahtar Kelimler: Maleik anhidrit-vinil asetat kopolimeri, Esterleşme

\section{The Synthesis and Characterization of Ester and Carboxly Salt of Maleic}

\section{Anhyride Vinyl AcetateCopolymer}

\begin{abstract}
With the study, The aim is increase thermal stability of copolymer derivatives. For this purpose, maleic anhydride-vinyl acetate (MAVA) copolymers; monoesters and carboxylate salt derivatives of its were obtained by reaction of maleic anhydride vinyl acetate copolymer with n-propyl alcohol, n-butyl alcohol and ammonia. Structural characterization of these derivatives was carried out by Fourier transform infrared spectroscopy (FTIR) and Thermogravimetric Analysis (TGA) was used at thermal analysis. In conclusion according to the TGA curve as compared to the heat stability and were found to be the most stable of the carboxylate derivatives of the ester derivatives of the least stable.
\end{abstract}

Keywords: Maleic anhydride-vinyl acetate, Esterification

\section{GíRiş}

Polimerler; hafif, ucuz, mekanik özellikleri çoğu kez yeterli, kolay şekillendirilebilen, değişik amaçlarda kullanıma uygun, dekoratif, kimyasal açıdan inert ve korozyona uğramayan maddelerdir [1].

Günümüzde kaynakları her geçen gün azalan doğal malzemelere alternatif olan polimerler yaygın bir uygulama alanına sahiptirler. Polimerlerin işlenme kolaylığı, mekanik davranışları, esnek yapıları ve düşük yoğunluğa sahip olmaları önemli avantajlarıdır [2].

Gelişen teknoloji ile beraber polimerik kompozitler daha çok elektronik elemanlar, otomotiv sanayi, uçak sanayi alanlarında kullanılmaya başlanmıştır. Polimerlerin oldukça yaygın

\footnotetext{
* Corresponding author. Email address: ukocyigit@ cumhuriyet.edu.tr 


\section{KOÇYIĞİT, ZENGİN}

kullanılabilmelerinin en önemli sebeplerinden biri de çok çeşitli özellikte polimerlerin sentezlenebilesi ve elde edilen bir polimerin eksik bulunan özelliğinin kimyasal modifikasyonla ya da karşımların hazırlanmasıyla değiştirilebilmesidir. Örneğin, elektronik elemanlarda kullanılan polimerlerin yüksek 1sıl iletkenliğe sahip olmaları istenmektedir, bu yüzden 1sıl iletken olan polimerler üzerine çalışmalar yapılmaktadır [3-5].

Çalışmamızın temelini teşkil eden Maleik anhidrit (MA), $\mathrm{C}_{4} \mathrm{H}_{2} \mathrm{O}_{3}$ genel formülüne sahip eşsiz bir elektron-alıcı monomerdir. MA içerikli kopolimerler serbest radikal polimerizasyon tepkimeleri ile başlatıcılar kullanılarak sentezlenmektedir. Polianhidritler olarak da bilinen MA kopolimerleri reaktif anhidrit halkası nedeniyle halka açılma tepkimeleri için oldukça elverişlidirler. Böylece su $\left(\mathrm{H}_{2} \mathrm{O}\right)$, alkol $(\mathrm{ROH})$, amin $\left(\mathrm{RNH}_{2}\right)$ ve amin türevleri gibi küçük mol kütleli moleküllerle modifikasyona uğrayabilirler. Bu özelliklerine ek olarak ekonomik olmaları da onları birçok alanda yaygın olarak kullanılabilir hale getirerek ticari olarak da artık ulaşılabilir haldedirler [6-7].

$\mathrm{Bu}$ çalışmada, maleik anhidrit-vinil kopolimerlerinde bulunan anhidirit grupları açılarak ester ve karboksilat türevlerinin elde edilmesi ile hazırlanan kopolimer türevlerinde 1sıya karşı dayanıklılı̆̆ı artırılmaya çalışılmıştır.

\section{MATERYAL VE METOD}

Maleik anhidrit-vinil asetat kopolimeri (MA-VA) elde etmek için kurutulmuş uzun bir deney tüpüne $19.6 \mathrm{~g}$ maleik anhidrid, $26.8 \mathrm{~mL}$ vinil asetat (1:1) ve $0.9 \mathrm{~g}$ da Azoizobutironitril (AIBN) konularak ve üzerine çözücü olarak bütil asetat eklenmiştir. Deney sıcaklığı olan $70{ }^{\circ} \mathrm{C}$ sıcaklıktaki su banyosunda deney tüpü iki saat bekletilmiş ve oluşan kopolimerden dolayı çözeltinin viskozitesi zamanla artmıştır. 2 saat bekledikten sonra tüp su banyosundan çıkarılarak soğumaya bırakılmıştır. Tüp içeriği yeterince soğuduktan sonra bir beherin içine boşaltılarak propanol ile çöktürülmüş ve maleik anhidrit-vinil asetat kopolimeri hekzan ile bir defa yıkanarak kurutulmuştur. [8].

Maleik anhidrit-vinil asetat n-propil ester ve n-bütil ester eldesi: MA-VA kopolimerinden her biri için 2 gram alınarak üzerine $35 \mathrm{~mL}$ dimetilformamid (DMF) ilave edilerek sicak su banyosunda 1 saat bekletilerek kopolimerlerin çözünmesi sağlanmıştır. Daha sonra karışımlara (1:4) oranında $100 \mathrm{~mL}$ n-propil alkol ve $100 \mathrm{~mL}$ n-bütil alkol ilave edilerek etkileşmeleri için sıcak su banyosunda bekletilmişler ve 12 saat sicak su banyosunda bekletildiklerinden sonra süzme işleme ile çökelekler alınmıştır [9]. Çökelekler küçük parçacıklara ayrılarak hegzan ile yıkanmış ve açık havada kurutulmuştur.

Maleik anhidrit vinil asetat n-propil karboksilat tuzu eldesi için Maleik anhidrit-vinil asetat n-propil esteri yeteri kadar benzende çözülmüştür. 3 gram kopolimer esteri ve $6 \mathrm{~mL} \% 90$ 'llk amonyak ( oran olarak 4.1, $\mathrm{NH}_{3}: \mathrm{MA}$ ) karışımı kopolimer tam çözüne kadar ilave edilmiş ve 1 saat kadar sıcak su banyosunda bekletildikten sonra çökelek karışımdan alınmıştır [10]. Çökelek 
küçük parçacıklara ayrılarak hegzan ile yıkanmıştır. Aynı işlemler Maleik anhidrit-vinil asetat nbütil karboksilat tuzu eldesi içinde yapılmıştır.

Elde Edilen Örneklerin Karakterizasyonu: $\mathrm{Bu}$ çalışmada sentezlenen tüm kopolimer ve türevlerinin çözücüleri araştırılmıştır. Bu amaçla sentezlenen her örnekten $5 \mathrm{mg}$ alınarak $20 \mathrm{~mL}$ dimetilformamid (DMF), tetrahidrofuran (THF), aseton (A), toluen (T), siklohekzanon (SH) ve su içine konulmuş ve oda sıcaklığında çözünüp çözünmedikleri kontrol edilmiştir.

Sentezlenen bileşiklerin yapılarının aydınlatılması için; sentezlenen bütün örneklerden $2 \mathrm{mg}$ alınarak $100 \mathrm{mg} \mathrm{KBr}$ ile agat havanda iyice karıştırılarak ögütülmüsstür. Daha sonra preslenerek Unicam Marka Mattson 1000 Model bir FTIR Spektrofotometresinde FTIR spektrumları alınmıştır.

Termogravimetrik Analiz (TGA) : $10{ }^{\circ} \mathrm{C} / \mathrm{dk}$ 1sıtma hızında ve $25 \mathrm{~cm}^{3} / \mathrm{dk}$ azot atmosferi akış hızında isıtılan maddede meydana gelen kütle kaybının sıcaklığın veya zamanın bir fonksiyonu olarak ölçülerek kaydedilmesidir. Isısal analiz sentezlenen türevlerin 1sısal kararlılığ ya da bileşimi hakkında bilgi sağlayıcı değiş̧ikliklerin takip etmek için kullanılmıştır.

$\mathrm{Bu}$ çalışmada her bir örnekten yaklaşık $10 \mathrm{mg}$ tartılmış ve $10^{\circ} \mathrm{C} / \mathrm{dk} 1$ sıtma hızında $25 \mathrm{~cm}^{3} / \mathrm{dk}$ akış hızında dinamik azot atmosferinde oda sıcaklığından $600{ }^{\circ} \mathrm{C}$ ye kadar 1sıtılarak Shimadzu marka TA-50 model bir Termogravimetri (TGA) cihazında kaydedilmiştir. Termogramlardan ısısal kriterler saptanmıştır. Elde edilen termogramların Freeman-Carroll yöntemine göre kinetik paremetreleri belirlenmiştir.

\section{SONUÇLAR VE TARTIŞMA}

Maleik anhidrit-vinil asetat kopolimerlerinin değişik çözücülerdeki çözünürlükleri ve renkleri Çizelge 1'de görülmektedir.

Çizelge 1. Maleik anhidrit-vinil asetat kopolimerlerinin değişik çözücülerdeki çözünürlükleri, renkleri (Dimetilformamid (DMF), tetrahidrofuran (THF), aseton (A), toluen $(\mathrm{T})$, siklohekzanon $(\mathrm{SH})$ ve $(+)$ : polimer çözünüyor (-) : polimer çözünmüyor.

\begin{tabular}{lccccccc}
\hline & THF & A & SH & DMF & T & Su & Renk \\
\hline MA-VA & + & + & + & + & - & - & Beyaz \\
MA-VA n-Propil alkol Ester & + & + & + & + & - & - & Açı sarı \\
MA-VA n-Bütil alkol Ester & + & + & + & + & - & - & Açı sarı \\
MA-VA n-Propil alkol Karboliksat Tuz & + & + & + & + & - & - & Açı sarı \\
MA-VA n-Bütil alkol KaboksilatTuz & + & + & + & + & - & - & Açı sarı \\
\hline
\end{tabular}

Verilere göre MA-VA kopolimerlerinin, bu kopolimerlerin ester ve karboksilat tuzu türevlerinin aynı tür çözücülerde gözlenen çözünürlüklerinde bir fark olmadığı anlaşılmıştır

Elde edilen Maleik anhidrit-vinil aseatat (MA-VA) kopolimerlerinin ve türevlerinin kimyasal yapısını aydınlatabilmek amacıyla FTIR spektrumları alınmıştır. Kıyaslamanın kolay yapılabilmesi için MA-VA'nin ester türevleri Şekil 1. de, MA-VA'nin karboksilat tuz türevleri bir arada Şekil 2. de gösterilmiştir. 


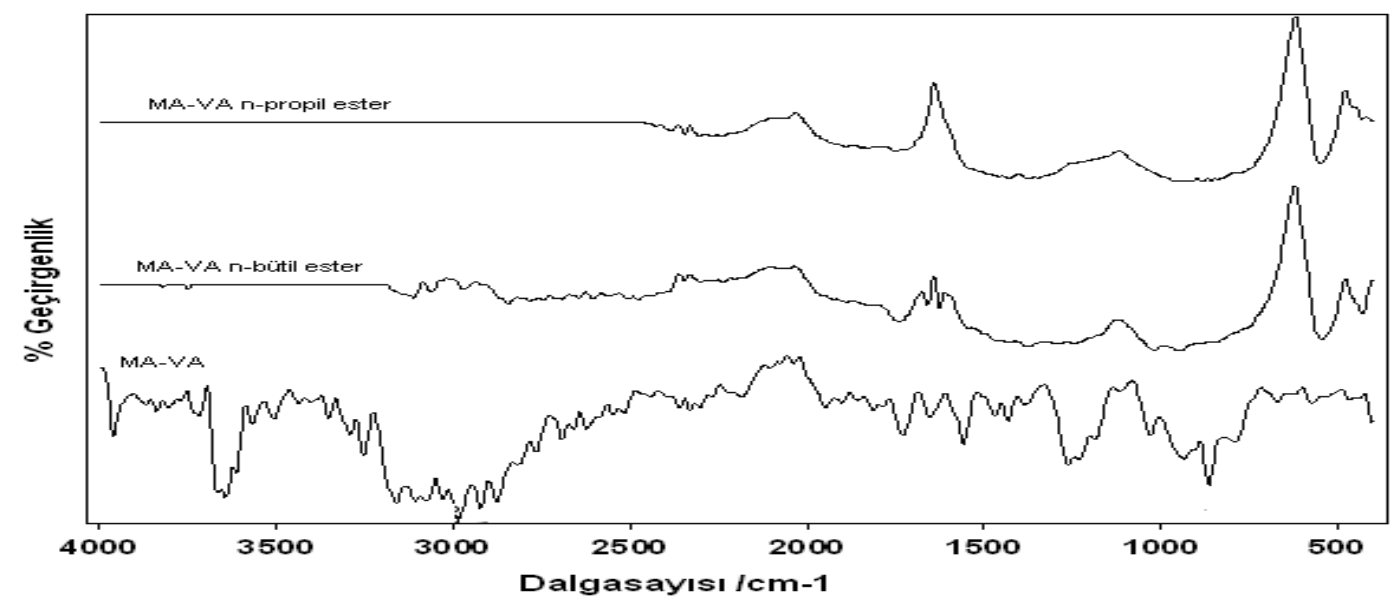

Şekil 1. MA-VA kopolimerinin, n-propil alkol esteri ve bütil alkol esterlerinin FTIR spektrumları.

Maleik anhidrit-vinil asetat kopolimeri için spektrum incelenmiş; $3400-3500 \mathrm{~cm}^{-1}$ de gözlenen piklerin molekül içi hidrojen bağının, 2950-3000 $\mathrm{cm}^{-1}$ 'de gözlenen piklerin alifatik $\mathrm{CH}_{3}$ ve $\mathrm{CH}_{2}$ yapılarının, 1855 ve $1804 \mathrm{~cm}^{-1}$, de anhidrit halkasının gösteren piklerin olduğu gözlenmiştir [11, 12, 13].

Maleik anhidrit-vinil asetat kopolimerinin n-propil alkol ve n-bütil alkol ile etkileşmesi sonucu oluşan MA-VA n-propil ester ve MA-VA n-bütil esterde anhidrit halkasına ait FTIR spektrumlarında $1804-1855 \mathrm{~cm}^{-1}$ ' de iki ayrı pikin kaybolması burada anhidrit halkasının açılmış olduğunu göstermiştir [12,13]. Söz konusu tepkime mekanizmaları aşağıda gösterildiği gibidir.

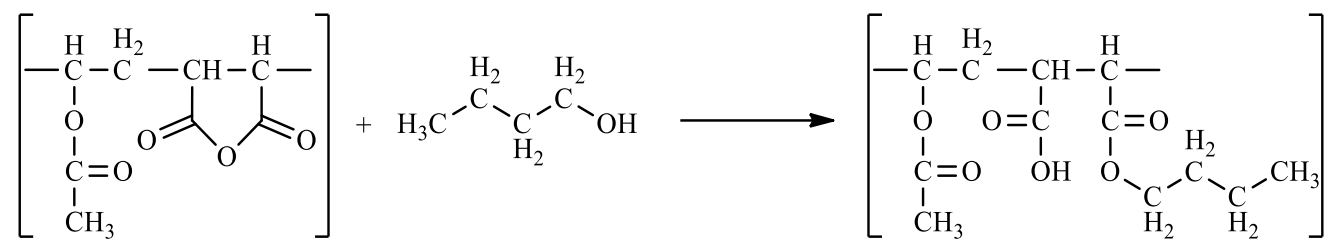

MA-VA

n-bütil alkol

MA-VA n-bütil ester

$\left[\begin{array}{l}\mathrm{C}-\mathrm{C}-\mathrm{CH}-\mathrm{C}-\mathrm{C}-\mathrm{O} \\ \mathrm{O} \\ \mathrm{C}=\mathrm{O} \\ \mathrm{C} \\ \mathrm{CH}_{3}\end{array}\right.$

MA-VA

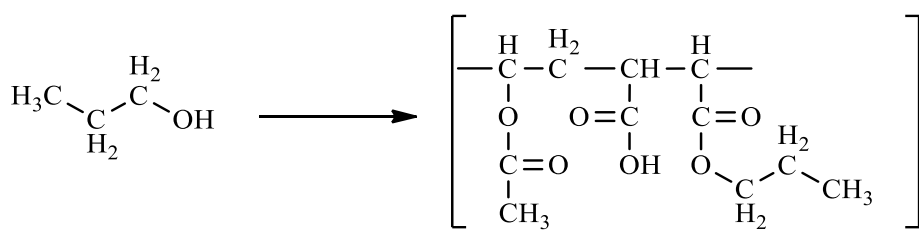

MA-VA n-propil ester 


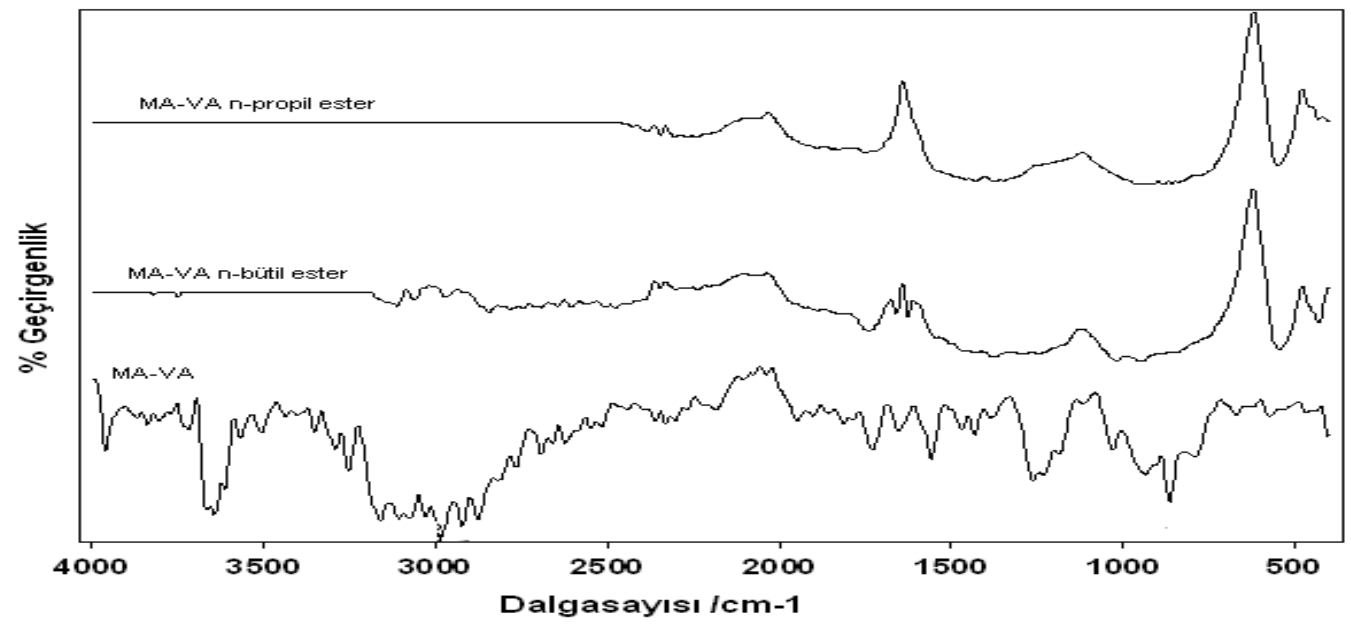

Şekil 2. MA-VA kopolimerinin, n-propil karboksilat tuzu ve n-bütil karboksilat tuzu IR spektrumları.

Maleik anhidrit-vinil asetat kopolimerinin ester türevleri MA-VA n-propil ester ve MA-VA n-bütil esterin amonyak ile etkileşmesi sonucu sentezlenen karboksilat tuzu türevleri n-propil karboksilat tuzu ve n-bütil karboksilat tuzunda anhidrit halkasına ait FTIR spektrumlarında 1804-1855 $\mathrm{cm}^{-1}$ 'de iki ayrı pikin kaybolması burada anhidrit halkasının açılmış olduğunu göstermiştir [12,13]. Tepkime mekanizmaları aşağıda gösterildiği gibidir. MA-VA ve tüm türevlerinin TGA eğrileri Şekil 3'de daha kolay kıyas yapılabilmesi için bir arada sunulmuştur.

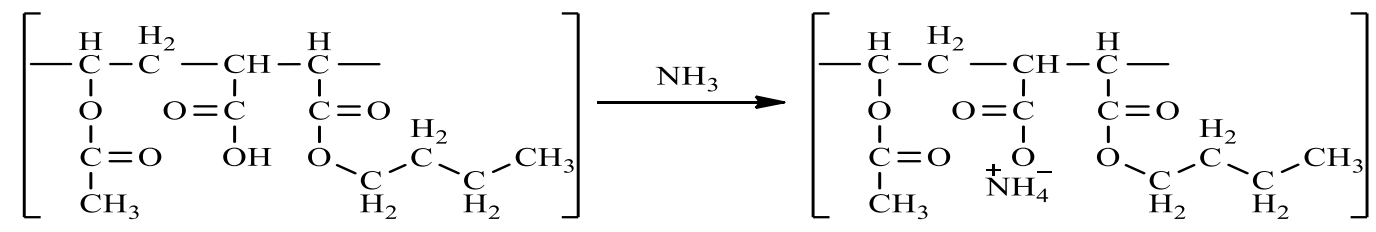

MA-VA n-bütil ester

MA-VA n-bütil karboksilat tuzu
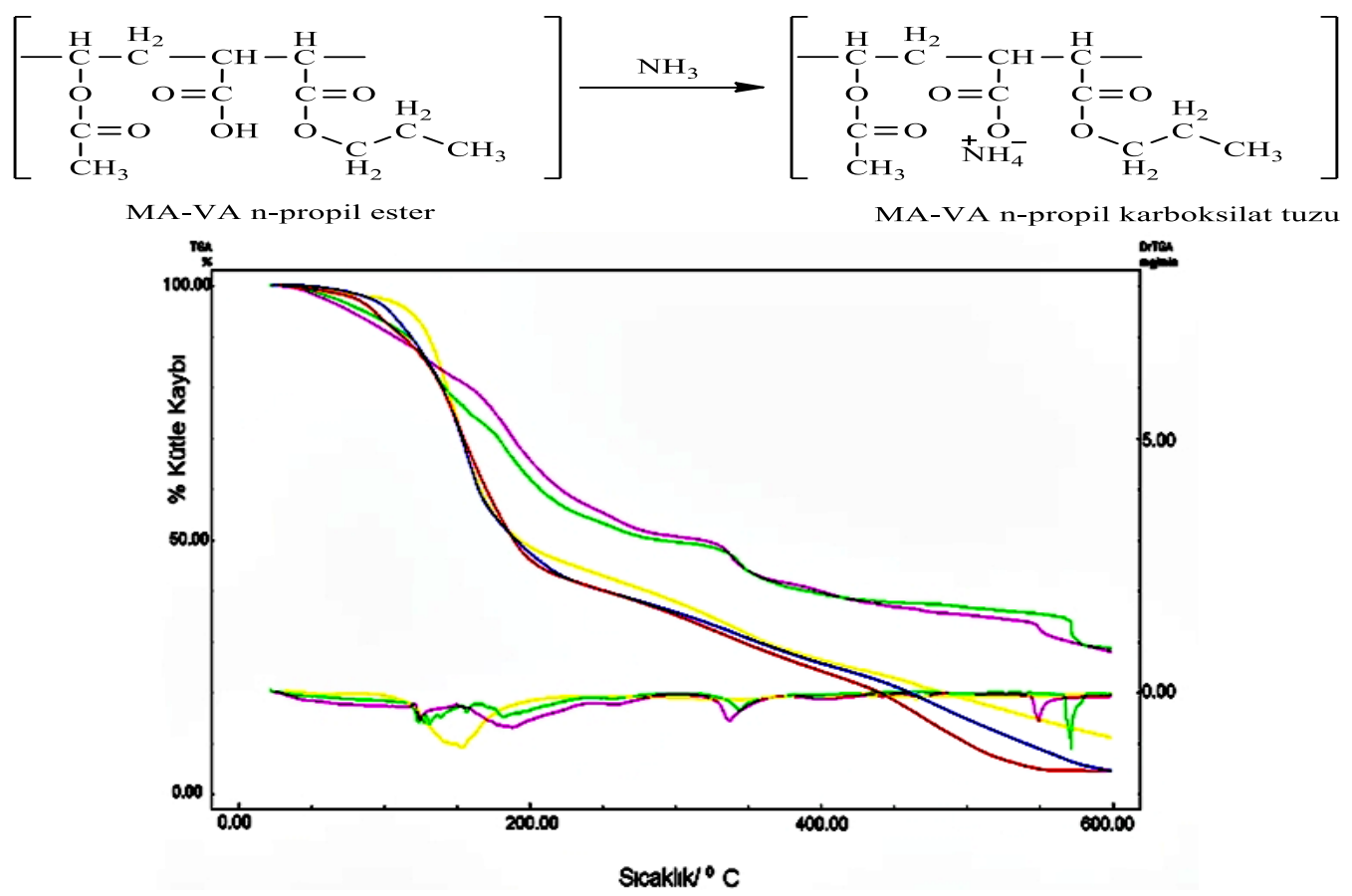

Şekil 3. - MA-VA, - MA-VA n-propil ester, - MA-VA n- bütil ester, - MA-VA n- propil tuz, -MA-VA n- bütil tuzu TGA eğrileri. 
Çalışmada TGA'ler için Maleik anhidrit-vinil asetat kopolimerinin ve ester türevlerinden her birinden $10 \mathrm{mg}$ tartılmış ve $10{ }^{\circ} \mathrm{C} / \mathrm{dk}$ 1sıtma hızında $25 \mathrm{~cm}^{3} / \mathrm{dk}$ akış hızında dinamik azot atmosferinde oda sıcaklığından $600^{\circ} \mathrm{C}$ ' ye kadar 1sıtılarak TGA eğrisi elde edilmiş ve bu eğriler incelenmiştir. Burada $200{ }^{\circ} \mathrm{C}$ 'den önceki bozunma adımı polimerde bulunan çözücü ve uçucu gruplardan $\left(\mathrm{H}_{2} \mathrm{O}, \mathrm{CO}_{2}, \mathrm{C}_{6} \mathrm{H}_{6} \ldots\right)$ kaynaklanmaktadır $[14,15]$.

Sonuç olarak $200^{\circ} \mathrm{C}$ 'den sonraki ikinci adımdaki bozunma polimerin degradasyon bozunma adımıdır. $\mathrm{Bu}$ adımda polimer 1sısal olarak parçalanmıştır. Kopolimer ve türevlerinin tepkime başlama sıcaklıkları $\left(\mathrm{T}_{\mathrm{i}}\right)$ incelendiğinde; MA-VA $237^{\circ} \mathrm{C}$, MA-VA propil esterinin $218^{\circ} \mathrm{C}$, MAVA bütil esterinin $204{ }^{\circ} \mathrm{C}$, MA-VA n-propil karboksilat tuzu $265{ }^{\circ} \mathrm{C}$, MA-VA n-bütil karboksilat tuzu $282{ }^{\circ} \mathrm{C}$ olduğu görülmüştür. Bu sonuçlardan MA-VA kopolimerinin isısal kararlığının ester türevlerine göre daha yüksek olduğu buna karşın karboksilat tuzu türevlerinden daha düşük olduğu ve esterleşmenin 1sısal kararlığı azalttığı buna karşın karboksilat tuzu oluşumunun 1sısal kararlılığını artırdığı anlaşılmıştır.

Karboksilat tuzlarına bakıldığında yaklaşık $340{ }^{\circ} \mathrm{C}$ ye kadar düzenli bir kütle kaybı görülmektedir buda bahsedildiği gibi yapıdaki 1sısal dönüşümden dolayı imidleşme olabilir. Bundan sonraki sıcaklıklarda polimer yapısında yapısal bir bozunma söz konusudur. Yaklaşık $350^{\circ} \mathrm{C}$ ' den sonra yapısal bozunma başlıyor. Bunun nedeni olarak ısısal etki yapıda kimyasal bir dönüşüm olması olasılığıdır. Bu dönüşümde $\mathrm{NH}_{4}$ gruplarından dolayı kondenzasyonla imid yapısal dönüşmesinden kaynaklanabileceği düşünülmektedir [16,17].

Ayrıca maleik anhidrid kopolimerlerinin 1sısal kararlılıklarının nicel olarak karşılaştırılabilmesi için de şekillerde verilen her termogramın Freeman Carroll yönetimine göre: $\quad \frac{\Delta \ln \frac{d C}{d t}}{\Delta \ln (1-C)}=n-\frac{E a}{R} \frac{\Delta \frac{1}{T}}{\Delta \ln (1-C)}$ (Freeman-Carroll eşitliği)

kinetik analizi yapılmış ve her bir örneğin 1sısal bozunma tepkimelerine ait kinetik parametrelerin bulunabilmesi için $[\Delta \ln (d C / d t) / \Delta \ln /(1-C)]$ değerlerinin $[\Delta(1-T) / \Delta \ln (1-C)]$ değerlerine karşı grafikleri çizilmiş ve Şekil 6, Şekil 7, Şekil 8, Şekil 9, Şekil 10'da verilmiştir [18].Bu grafiklerden elde edilen doğrunun dik ekseni kesim noktas1 1sısal bozunma tepkimelerinin tepkime dereceleri, $n$; eğim den ise $E_{a} / R$ oranları bulunmuştur. Buradan da isısal bozunma tepkimesinin aktifleşme enerjisi Ea hesaplanmıştır [14,15]. Elde edilen tüm kinetik parametreler Çizelge 3'de sunulmuştur.

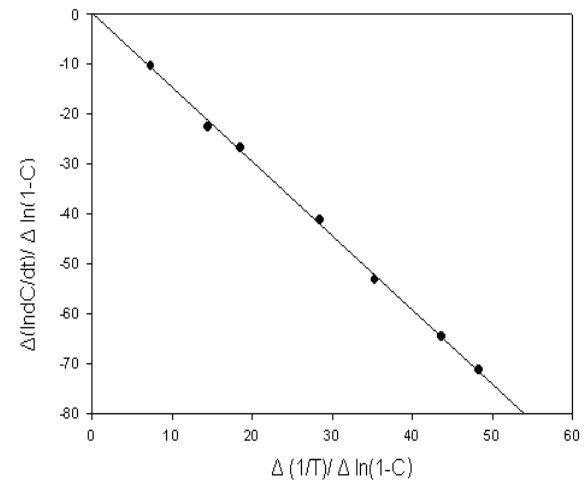

Şekil 6. MA-VA n-bütil ester kopolimerinin FreemanCarroll eşitliğine göre Aktivasyon enerjisinin belirlenmesi.

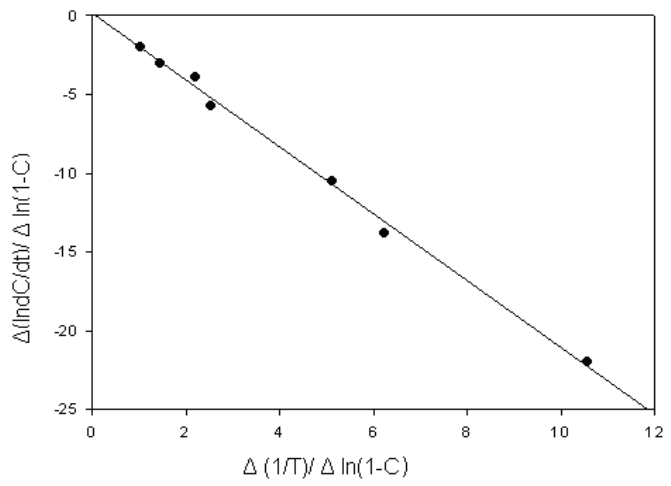

Şekil 7. MA-VA kopolimerinin Freeman-Carroll eşitliğine göre Aktivasyon enerjisinin belirlenmesi. 


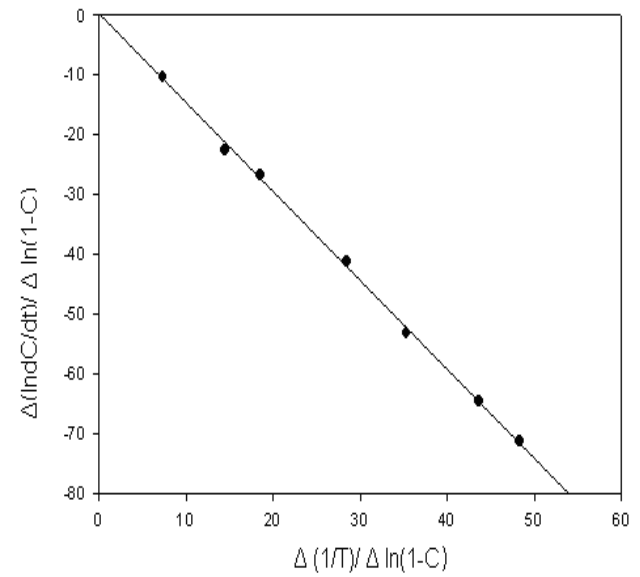

Şekil 8. MA-VA n-propil ester kopolimerinin Freeman Carroll eşitliğine göre aktivasyon enerjisinin belirlenmesi.

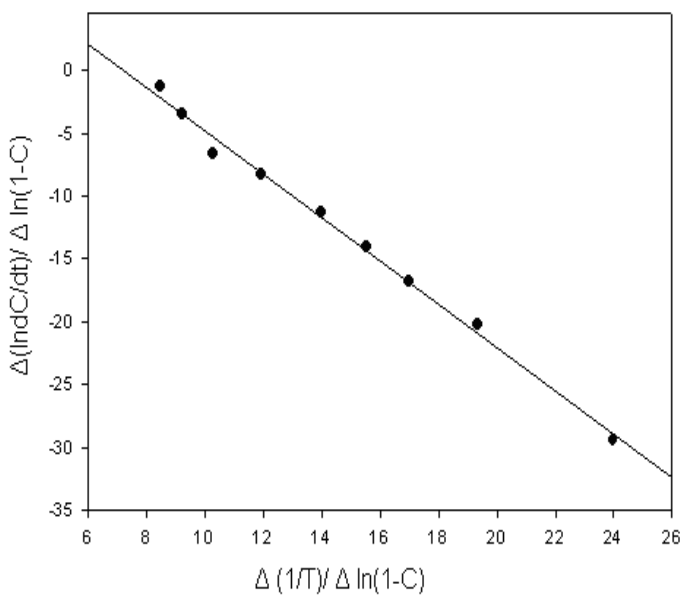

Şekil 9. MA-VA n-bütil karboksilat tuzunun Freeman Carroll eşitliğine göre Aktivasyon enerjisinin belirlenmesi.

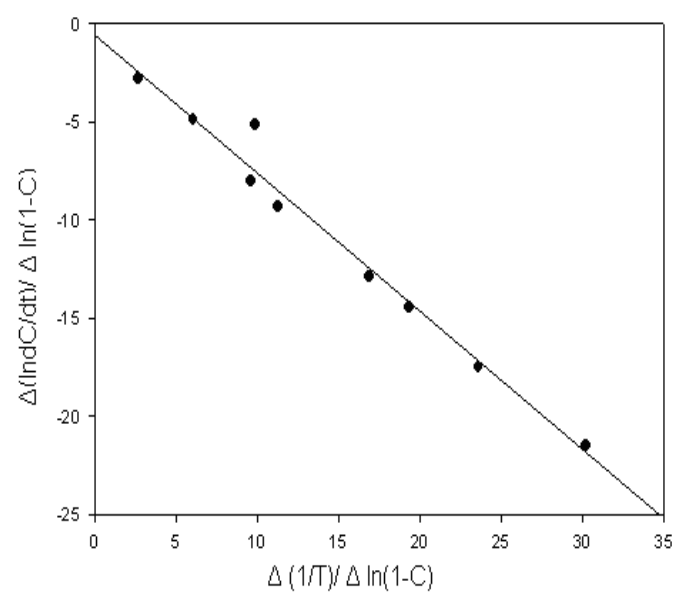

Şekil 10. MA - VA n-propil karboksilat tuzunun Freeman - Carroll eşitliğine göre Aktivasyon enerjisinin belirlenmesi.

Çizelge 2. Kopolimerler ve türevlerinin TGA verileri

\begin{tabular}{lllllll}
\hline & $\mathbf{T}_{\mathbf{i}} /{ }^{\circ} \mathbf{C}$ & $\mathbf{T}_{\mathbf{f}} /{ }^{\circ} \mathbf{C}$ & $\mathbf{T}_{\mathbf{h}} /{ }^{\circ} \mathbf{C}$ & $\mathbf{T}_{\mathbf{m}} /{ }^{\circ} \mathbf{C}$ & $\mathbf{C m}$ & $\mathbf{R m}$ \\
\hline MA-VA & 237,3 & 175,28 & 190,36 & 156,52 & 67,01 & 1,00 \\
MA-VA n-propil Ester & 218,5 & 194,12 & 186,84 & 153,7 & 70,4 & 0,66 \\
MA-VA n-bütil Ester & 204,8 & 172,26 & 192,48 & 153,10 & 69,63 & 1,11 \\
MA-VA n-propil Tuz & 265,6 & 229,41 & 282,02 & 130,43 & 84,57 & 0,62 \\
MA-VA n-Bütil Tuz & 282,3 & 242,47 & 308,11 & 187,54 & 70,46 & 0,70 \\
\hline
\end{tabular}

Maleik anhidrit kopolimerlerinin 1sısal kararlılıklarını birbiri ile nitel olarak kıyaslayabilmek için, termogramlardan tepkime başlama sıcaklığ $\breve{g}_{1}\left(\mathrm{~T}_{\mathrm{i}}\right)$, yarı ömür sicaklığ ${ }_{1}\left(\mathrm{~T}_{h}\right)$, tepkime sonlanma sıcaklığ $\left(\mathrm{T}_{\mathrm{f}}\right)$, maksimum hız $(\mathrm{Rm})$ ve maksimum hızda geriye kalan madde miktarı (Cm) gibi isısal analiz kriterleri elde edilmiş ve edilen bulgular Çizelge 2 de verilmiştir.

Maleik anhidrit-vinil asetat kopolimerlerinin ve türevlerinin TGA verileri incelenmiş ve yukarıdaki çizelgede sunulmuştur. Buna göre tepkimeye başlama sıcaklığına göre kopolimerler sıralandığında MA-VA n-bütil ester $<$ MA-VA n-propil ester $<$ MA-VA $<$ MA-VA n-propil tuz MA-VA n-propil tuz < MA-VA n-Bütil Tuz şeklinde olduğu bulunmuştur. 
Maksimum hızda geriye kalan madde miktarına kopolimer sıralandığında MA-VA $<$ MA-VA nbütil ester $<$ MA-VA propil ester $<$ MA-VA n-bütil tuz $<$ MA-VA n-propil tuz şeklinde olduğu bulunmuştur.

Çizelge 3. Kopolimer ve türevlerinin Freeman - Carroll yöntemiyle hesaplanan kinetik parametreleri

\begin{tabular}{lccc}
\hline & $\mathbf{N}$ & $\mathbf{r}$ & $\mathbf{E} / \mathbf{k J ~ m o l}^{-1}$ \\
\hline MA-VA & 0,8 & 0,9910 & 183,02 \\
MA-VA n-propil Ester & 1,5 & 0,9688 & 132,8 \\
MA-VA n-bütil Ester & 0,1 & 0,9987 & 124,76 \\
MA-VA n-bütil Tuz & 1,96 & 0,9972 & 149,11 \\
MA-VA n-propil Tuz & 0,18 & 0,9945 & 61,73 \\
\hline
\end{tabular}

Maleik anhidrit-vinil asetat kopolimerleri ve türevlerinin kinetik parametreleri incelenmiş ve hesaplanan kinetik parametrelerde yukarıdaki çizelgede sunulmuştur. Çizelgede sunulduğu gibi kopolimerlerin tepkime derecesi olan ' $\mathrm{N}$ ' değerlerinin 0-2 aralığında çıkması teorik bilgilerle paralel olduğu sonucunu göstermiştir. Tüm kopolimerler için aktifleşme enerjileri hesaplanmıştır. Aktifleşme enerjisine göre kopolimer sıralandığında MA-VA n-propil tuz < MA-VA n-bütil ester < MA-VA propil ester < MA-VA n-bütil tuz < MA-VA olduğu bulunmuştur. Yapılan tüm işlemler için korelasyon katsayısı hesaplanmış ve bulunan tüm değerlerin bire çok yakın çıkması yapılan işlemlerin doğru olduğunu göstermiştir.

Sonuç olarak MA-VA kopolimerlerinin, bu kopolimerlerin ester türevlerinin ve karboksilat tuzu türevlerinin aynı tür çözücülerde gözlenen çözünürlüklerinde bir fark olmadığ anlaşılmıştır.

FTIR'ların yorumu; spektrumların değerlendirilmesi sonucu maleik anhidritin vinil aseatatın kopolimerleştiği, polimerleşme tepkimelerinin maleik anhidritin ve içerdiği çift bağlar üzerinden yürüdüğü anlaşılmıştır.

Maleik anhidrit vinil asetat kopolimeri için spektrum incelenmiş; $3400-3500 \mathrm{~cm}^{-1}$ de gözlenen piklerin molekül içi hidrojen bağının, 2950-3000 $\mathrm{cm}^{-1}$, de gözlenen piklerin alifatik $\mathrm{CH}_{3}$ ve $\mathrm{CH}_{2}$ yapılarının, $1804-1855 \mathrm{~cm}^{-1}$ 'de anhidrit halkasının olduğu gözlemlenmiştir.

Maleik anhidrit vinil asetat kopolimerinin n-propil alkol ve n-bütil alkol ile etkileşmesi sonucu oluşan MA-VA n-propil ester ve MA-VA n-bütil esterde anhidrit halkasına ait FTIR spektrumlarında $1804-1855 \mathrm{~cm}^{-1}$ ' de iki ayrı pikin kaybolması burada anhidrit halkasının açılmış olduğunu göstermiştir.

Maleik anhidrit vinil asetat kopolimerinin ester türevleri MA-VA n-propil ester ve MA-VA n-bütil esterin amonyak ile etkileşmesi sonucu sentezlenen karboksilat tuzu türevleri n-propil karboksilat tuzu ve n-bütil karboksilat tuzunda anhidrit halkasına ait FTIR spektrumlarında 1804-1855 $\mathrm{cm}^{-1}$ 'de iki ayrı pikin kaybolması burada anhidrit halkasının açılmış olduğunu göstermiştir.

Aşağıda anhidrit vinil asetat kopolimerlerinden türetilen ester ve karboksilat tuzu türevlerinin tepkime mekanizmaları topluca sırasıyla Şema 1 de sunulmuştur. 
Şema 1. Maleik anhidrit-stiren kopolimerlerinden türetilen ester ve karboksilat tuzu kopolimerlerinin tepkime mekanizmaları.

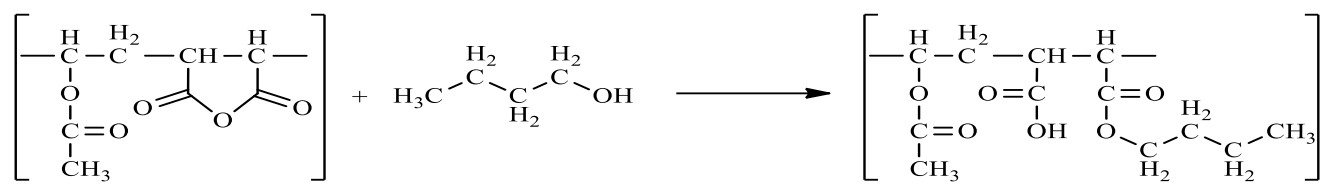

MA-VA n-bütil alkol MA-VA n-bütil ester<smiles>CCCOC(=O)C(C)C(CC(C(=O)O)C(C)C)C(=O)OCCCO</smiles>

MA-VA n-propil alkol MA-VA n-propil ester

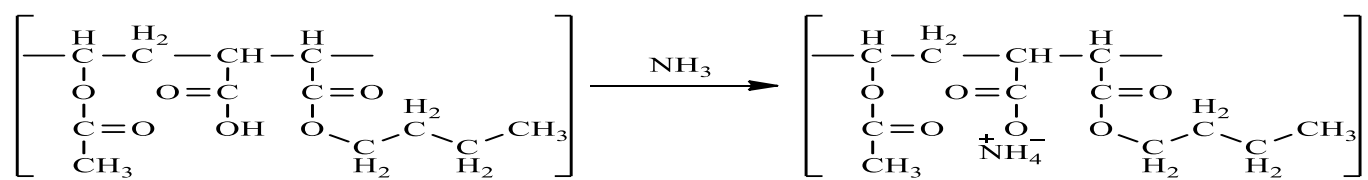

MA-VA n-bütil ester

MA-VA n-bütil karboksilat tuzu

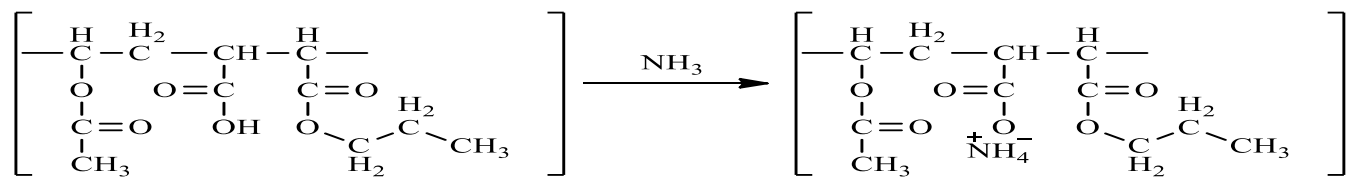

MA-VA n-propil ester

MA-VA n-propil karboksilat tuzu

Kopolimer ve türevlerinin tepkime başlama sıcaklıkları $\left(\mathrm{T}_{\mathrm{i}}\right)$ incelendiğinde;

MA-VA $237{ }^{\circ} \mathrm{C}$, MA-VA propil esterinin $218{ }^{\circ} \mathrm{C}$, MA-VA bütil esterinin $204{ }^{\circ} \mathrm{C}$ olduğu görülmüştür. Bu sonuçlardan MA-VA kopolimerinin isısal kararlığının ester türevlerine göre daha yüksek olduğu bunun ester gruplarının daha düşük sıcaklıkta kopolimerden kopmasından kaynaklandığ 1 , buda 1sısal kararlılığı azalttığı anlaşılmıştır.

MA-VA $237{ }^{\circ} \mathrm{C}$, MA-VA n-propil karboksilat tuzu $265^{\circ} \mathrm{C}$, MA-VA n-bütil karboksilat tuzu $282{ }^{\circ} \mathrm{C}$ olduğu görülmüştür. $\mathrm{Bu}$ sonuçlardan MA-VA kopolimerinin 1sısal kararlığının karboksilat tuzu türevlerine göre daha düşük olduğu karboksilat tuzu oluşumunun isısal kararlılı̆̆ $\operatorname{artırdığı~anlaşılmıştır.~}$

Karboksilat türevleri 1sıya karşı daha dayanıklı olduğu buna karşın ester türevlerin ısıya karşın dayanıksız olduğu sonucuna varılmıştır. Kopolimerin ve ester türevlerinin kullanım yerlerine göre 1sıya karşı dayanıksız olarak görülüyorsa bunları dayanıklı hale getirmek için karboksilat türevlerinin oluşturmasını faydalı olcağı düşünülmektedir.

\section{TEŞEKKÜR}

$\mathrm{Bu}$ çalışmada maddi destek sağlayan Cumhuriyet Üniversitesi Araştırma Fonuna (F-268) ve Laboratuvar imkanı sağlayan Cumhuriyet Üniversitesine Fen Fakültesi Kimya bölümüne çok teşekkür ederim. 


\section{KAYNAKLAR}

[1] Saçak M., Polimer Kimyas1, Anakara Üniversitesi, Gazi Kitabevi, 2002.

[2] Şahmetlioğlu, E., Toppare, L., Demir, D. 2007. Metal İçerikli İletken Polimerlerin Sentez ve Karakterizasyonu adlı Tübitak projesi sonuç raporu, Proje No: 104M406, Niğde.

[3] Tavman, Đ.H., Turgut, A. Mikro ve nano boyutlu tanecik katkı11 polimer kompozitlerin mekanik özellikleri, Proceedings of 11th International Materials Symposium, April 19-21, 2006, Denizli, Türkiye 570-575.

[4] Zengin H. B., Basan S., Ekberov . "Maleik anhidrit kopolimerinin amid ve imid türevlerinin sentezi ve 1sısal davranışları" C.Ü Fen Bilimleri Enstitüsü Dergisi,2006, 26-2.

[5] Boztuğ A.. Bazı maleik anhidrit terpolimerlerinin ester türevlerinde bilişimin 1sısal ve termomekanik özelliklere etkisi. Doktora tezi, Cumhuriyet Üniversitesi Fen-Bilimleri Enstitüsü Kimya Ana Bilim Dal1, Sivas,1999.

[6] Popescu I, Suflet DM, Pelin IM, Chitanu GC. Biomedical applications of maleic anhydride copolymers. Rev Roum Chim 2011;56: 173-88.

[7] Gülderen K., 'Bazı Maleik Anhidrit İçeren Kopolimerlerin Amin Yapılı İlaç Etken Maddeleri İle Türevlendirilmesi, Yapısal Karakterizasyonu ve Biyolojik Aktiviteleri'Marmara Pharmaceutical Journal 19: 121-125, 2015

[8] Atıc1, G. Oya, Akar, A. ve Rahımıan, R. " Modification of Poly( Maleic anhyride-costyrene) with Hydroxyl Containing Compounds", Turk J Chem 25, TÜBITTAK,2001, 259-266.

[9] Gamal, R. Saad, Rania E. Morsi, Sayed Z. Mohammady ve Maher Z. Elsabee, J Polym Res,2008, 15:115-123.

[10] V. P. Lesnyak, D. I. Shiman, L. V. Gaponik, F. N. Kaputskii,A. I. Lamotkin, and Zh. V. Bondarenko. 'Copolymers of the C9 Hydrocarbon Fraction of Liquid Pyrolysis Products with Maleic Anhydride and Their Esterification Products as Additives to Paper Pulp', Belarus, 2006.

[11] Zengin H. Bayram. 'Bazı maleik anhidrit kopolimerlerinin değişik amid ve imid türevlerinin sentezi ve 1sısal bozunması' Doktora tezi, Cumhuriyet Üniversitesi Fen-Bilimleri Enstitüsü Kimya Ana Bilim Dalı, Sivas,1999.

[12] FTIR atlas1 "An infrared spectroscopy atlas fort he coatings industry (Fedaration of Societies for coatings Technologis)"

[13] McNeill, I.C., Polischuk, A.Y. ve Zaikov, G.E.. Thermal Degradation Studies of Alternating Copolymers: Maleic anhydride- Vinyl acetate, Polymer Degradation and Stability, 1992,37, 223-232.

[14] Sroog C. E. “Polyimides” Polym. Sci. 1991.16, 561-694.

[15] Kim woo-Sik, Seo Kwan-Ho Macromol. Rapid Commun. 17, 1996, 835-841.

[16] Padwa Allen R; C.W. Macosko; K.A. Woiske and Y.Sasaki, 'Kinetic of amine anhyride reactions for reactive processing'.Polym.Prepr.1993,34-3,842-843.

[17] Rzaev Z.M. . 'Maleik Anhidrid Kopolimeri’” Baku,1984.

[18] Freeman, E.S. ve Carroll, B.. The Application of Thermoanalytical to Reaction Kinetics. The Thermogravimetric Evaluation of The Kinetic Of The Decomposition of Calcium Oxalate Monohydrate., J. Phys. Chem..1958, 62,394-396 